\title{
FLORA DA BAHIA: MANILKARA ADANS (SAPOTACEAE) - CONSIDERAÇÕES SOBRE A ANATOMIA FOLIAR
}

\author{
Ana Flávia Trabuco Duarte ${ }^{1}$ e Cláudia Elena Carneiro ${ }^{2}$ \\ 1. Bolsista PIBIC/CNPq, Graduanda em Ciências Biológicas, Universidade Estadual de Feira de Santana, e-mail: \\ flavia.trabuco@hotmail.com \\ 2. Orientadora, Departamento de Ciências Biológicas, Universidade Estadual de Feira de Santana, e-mail: \\ carneiro@uefs.br
}

PALAVRAS-CHAVE: anatomia; taxonomia; micromorfologia

\section{INTRODUÇÃO}

A família Sapotaceae ocupa um lugar de destaque na flora do Brasil, com 232 espécies, sendo que destas, 101 são endêmicas do país, distribuídas em 12 gêneros (Carneiro et al., 2016). Para a Bahia, atualmente está registrada a ocorrência de 77 espécies, e 11 gêneros (Carneiro et al., 2016). A família, é caracterizada por representantes arbóreos e arbustivos, podendo apresentar estípulas ou não, as folhas simples são geralmente alternas e agrupadas no topo dos ramos, as flores não são vistosas, podendo ser solitárias ou agrupadas, com sépalas em número de 4-12, geralmente livres ou unidas na base, e fruto do tipo baga (Pennington, 1990), sendo facilmente reconhecida pela combinação do látex, com o arranjo e venação das folhas (Gentry, 1993). Possui uma distribuição predominantemente pantropical e tem importância econômica devido a produtos como o látex, a madeira e os frutos carnosos, estes últimos fazendo parte da dieta de aves e primatas (Pennington, 1990). Segundo Metcalfe e Chalk (1950, 1979), a taxonomia da família é confusa devido a falta de dados claros, principalmente no que se refere a distinção intergenérica.

Manilkara Adans. é o quarto maior gênero da família, sendo representado por cerca de 30 espécies no Neotrópico (Pennington, 1990). É caracterizado pelo cálice em duas séries, presença de estaminódios e a forma do hilo (Pennington, 1990). Das 16 espécies que ocorrem no Brasil, nove são registradas para a Bahia (Almeida Jr., 2015).

Estudos anatômicos podem ser utilizados como uma ferramenta para a caracterização taxonômica de grupos, para tentar solucionar os problemas de delimitação das espécies do gênero, e a folha é o órgão mais utilizado para esta caraterização. Tendo em vista as dificuldades de delimitação interespecíficas do gênero Manilkara, este trabalho buscou contribuir para a caracterização do grupo através de estudos antômicos da folha.

\section{METODOLOGIA}

Primeiramente, foi realizado o levantamento das espécies de Manilkara ocorrentes na Bahia, de acordo com os registros para o estado na Lista de Espécies da Flora do Brasil (Flora do Brasil 2020 em construção, 2016). Em seguida, foi realizada a busca dos espécimes disponíveis no Herbário da Universidade Estadual de Feira de Santana (HUEFS) através de consulta virtual e física ao acervo. A identificação das espécies foi realizada através de chaves de identificação elaboradas por especialistas do gênero. Para o estudo anatômico, foram utilizados quinze espécimes coletados em diferentes ambientes da Bahia. No processamento anatômico padrão, foram utilizadas folhas inteiras e totalmente expandidas, as quais foram reidratadas por meio de aquecimento em meio aquoso e glicerina a $50 \%$ durante três minutos. Todo o material foi armazenado em álcool a 70\% (Johansen, 1940). Posteriormente, as folhas foram submetidas a solução de hidróxido de potássio a $2 \%$ durante 24 horas para distensão celular. A lâmina foliar e o pecíolo foram seccionados transversalmente à mão livre, clarificados com hipoclorito de sódio a $10 \%$ e corados com azul de astra a $1 \%$ e 
safranina a 1\% (9:1) (Kraus \& Arduin, 1997). Para o estudo da epiderme foi empregada a técnica de Jeffrey, que utiliza a submersão de fragmentos foliares em solução contendo partes iguais de ácido nítrico a 10\% e ácido crômico a 10\% (Macêdo, 1997). As amostras de epiderme foram coradas com safranina a $1 \%$ e montadas em lâminas semipermanentes. As lâminas com as amostras foram analisadas qualitativa $\mathrm{e}$ quantitativamente em microscopia de luz, sendo que as medidas foram tomadas sob a objetiva de $40 \mathrm{X}$ com o auxílio de ocular micrométrica. Todas as amostras foram fotomicrografadas para confecção de pranchas ilustrativas com os caracteres anatômicos diagnósticos.

\section{RESULTADOS E DISCUSSÃO}

Como resultado inicial, foram identificadas sete espécies de Manilkara para a Bahia: Manilkara descrescens T.D. Penn.; Manilkara multifida T.D. Penn.; Manilkara rufula (Miq.) H.J.Lam; Manilkara salzmannii (A.DC.) H.J. Lam; Manilkara triflora (Allemão) Monach; Manilkara zapota (L.) P.Royen; e Manilkara sp. Essa última ainda não foi devidamente identificada. Os dados anatômicos obtidos estão sintetizados na Tabela 1. Todas as espécies analisadas apresentaram epiderme unisseriada, feixes de esclereides ao redor do feixe vascular, cutícula e laticíferos associados a nervura central. As características que diferiram nas espécies foram: presença/ausência de camada subepidérmica, número de estratos de parênquima lacunoso e paliçádico, e contorno da parede anticlinal das células da epiderme.

Tabela 1. Principais características anatômicas das folhas de sete espécies de Manilkara Adans. (Sapotaceae) ocorrentes no estado da Bahia.

\begin{tabular}{lccccccc}
\multicolumn{1}{c}{ Caracteres } & $\mathbf{1}$ & $\mathbf{2}$ & $\mathbf{3}$ & $\mathbf{4}$ & $\mathbf{5}$ & 6 & $\mathbf{7}$ \\
\hline Flanges cuticulares na epiderme & + & + & + & - & - & - & + \\
Paredes anticlinais retas & + & + & + & - & + & - & + \\
Paredes anticlinais sinuosas & - & - & - & + & - & + & - \\
Mesofilo dorsiventral & + & + & + & + & + & + & + \\
Número de camadas de parênquima & 2 & 3 & 3 & 3 & 2 & 2 & 2 \\
paliçádico & & & & & & & \\
Tricomas & - & + & + & + & + & + & + \\
Camada subepidérmica & - & - & + & + & - & + & + \\
\hline
\end{tabular}

Legenda: 1. Manilkara descrescens T.D. Penn., 2. Manilkara multifida T.D. Penn.,3. Manilkara rufula (Miq.) H.J.Lam, 4. Manilkara salzmannii (A.DC.) H.J. Lam., 5. Manilkara triflora (Allemão) Monach., 6. Manilkara zapota (L.) P.Royen., 7. Manilkara sp. $(+)=$ presente; $(-)=$ ausente.

As espécies apresentaram epiderme unisseriada e estômatos somente na face abaxial. Segundo Menezes et al. (2006), a folha hipoestomática evidencia uma característica referente a plantas que necessitam de um ambiente nem muito seco, nem muito úmido, chamadas de mesófitas. $\mathrm{O}$ número de estratos do parênquima paliçádico variou de dois a três. Algumas espécies possuem uma camada subepidérmica de origem ontogenética não conhecida, que foi utilizada como caráter taxonômico. A presença de uma camada subepidérmica, segundo Esau (1977), pode ter função de armazenamento de água, quando associada a cutícula espessa e ao parênquima paliçádico possuindo duas camadas, podendo significar uma adaptação xeromórfica. Em todas as espécies houve a presença de esclereide por todo o mesofilo e ao redor do feixe vascular que estão associadas a sustentação da estrutura foliar (Esau, 1977), e é característico do gênero Manilkara, como citado por Metcalfe \& Chalk (1983). Quanto ao tipo de feixe e de mesofilo, ocorrem o tipo colateral e dorsiventral, respectivamente, o que segundo Metcalfe \& Chalk (1983) é característico da família Sapotaceae. Foram observados 
laticíferos associados a região da nervura central, que está de acordo com Metcalfe \& Chalk (1950), os quais citam para a família Sapotaceae a presença de material semelhante a resina ou borracha.

\section{CONSIDERAÇÕES FINAIS}

Através dos estudos realizados foi possível observar características anatômicas do gênero que são comuns a todas as espécies podendo ser uteis na delimitação do gênero, tais como mesofilo dorsiventral, feixe vascular colateral, esclereides circundando a nervura central e dispostas ao longo do mesofilo, e laticíferos associados a nervura central. Além disso, há características que podem ser utilizadas taxonomicamente para distinguir as espécies, tais como o tipo de contorno das células epidérmicas, o número de camadas de parênquima paliçádico e de parênquima lacunoso, o formato e a disposição das células de parênquima lacunoso, presença ou ausência de camada subepidérmica, e posição do bordo. O estudo ainda está em andamento buscando caracterizar todas as espécies de Manilkara que ocorrem no estado da Bahia, de modo a contribuir para a delimitação das espécies desse gênero.

\section{REFERÊNCIAS}

ALMEIDA JR., E.B. Manilkara. In Lista de Espécies da Flora do Brasil. 2015 [online]. Homepage: http://reflora.jbrj.gov.br/jabot/floradobrasil/FB14473.

CARNEIRO, C.E.; ALVES-ARAUJO, A.; ALMEIDA JR., E.B.; TERRA-ARAUJO, M.H. 2016 [online]. Sapotaceae. In Lista de Espécies da Flora do Brasil. Homepage: http://reflora.jbrj.gov.br/jabot/floradobrasil/FB217.

ESAU, K. 1977. Anatomy of seed plants. New York, John Wiley \& Sons, 576p.

FLORA DO BRASIL 2020 EM CONSTRUÇÃO. 2016. [online]. Jardim Botânico do Rio de Janeiro. Homepage: http://floradobrasil.jbrj.gov.br.

GENTRY, A.H. 1993. A field guide to the families and genera of woody plants of northeast South America. Washington, D.C.: Conservation International, 920p.

JOHANSEN, D.A. 1940. Plant Microtechnique. New York, Mc. Graw Hill Book, $523 p$.

KRAUS, J.E.; ARDUIN, M. 1977. Manual Básico de Métodos em Morfologia Vegetal. Rio de Janeiro, Edur, 198p.

MACÊDO, N.A. 1997. Manual de Técnicas em Histologia Vegetal. Feira de Santana, Universidade Estadual de Feira de Santana, 60p.

MENEZES, L.N.; SILVA, C.D.; PINNA, M.A.F.G. 2006. Folha. In: APPEZZATODA-GLÓRIA, B. \& CARMELLO-GUERREIRO, S.M. Anatomia Vegetal. Viçosa, UFV, 404p.

METCALFE, C.R.; CHALK, L. 1950. Anatomy of Dicotiledons: Leaves, Stem, and Wood in Relation to Taxonomy with Notes on Economic Uses. v.2. Claredon Press, Oxford,1500p.

METCALFE, C.R.; CHALK, L. 1979. Anatomy of the Dicotyledons: Systematic Anatomy of Leaf and Stem, with a Brief History of the Subject. v.1. 2ed. Claredon Press, Oxford,806p.

METCALFE, C.R.; CHALK, L. 1983. Anatomy of the Dicotyledons. v.1. 2ed. Clarendon Press, Oxford,668p.

PENNINGTON, T.D. 1990. Sapotaceae. In Flora Neotropica, New York, v.52, 770p. 